\title{
The role of membrane acid/base transporters and carbonic anhydrases for cellular $\mathrm{pH}$ and metabolic processes
}

\author{
Joachim W. Deitmer ${ }^{1}{ }^{*}$, Shefeeq M. Theparambil ${ }^{1}$, Iván Ruminot ${ }^{1}$ and Holger M. Becker ${ }^{2}$ \\ General Zoology, FB Biology, University of Kaiserslautern, Kaiserslautern, Germany \\ ${ }^{2}$ Zoology/Membrane Transport, FB Biology, University of Kaiserslautern, Kaiserslautern, Germany \\ ${ }^{*}$ Correspondence: deitmer@biologie.uni-kl.de
}

Edited by:

Avital Schurr, University of Louisville, USA

Reviewed by:

Bernardo Victor Alvarez, Universidad Nacional De La Plata, Argentina

Mitchell Chesler, New York University School of Medicine, USA

Eva Maria Ruusuvuori, University of Helsinki, Finland

Keywords: pH, bicarbonate, lactate, transport metabolon, metabolism

\section{ACIDOSIS AND PROTON HOMEOSTASIS IN CELLS AND TISSUES}

Acidosis in the brain may severely impair a variety of functions, including synaptic transmission, metabolic energy supply, membrane transport and other processes (Ruusuvuori and Kaila, 2014).

Transport of acid-base equivalents across the cell membrane of neurons and glial cells also results in $\mathrm{pH}$ changes in the extracellular spaces. Cytosolic and extracellular buffer capacity and the activity of carbonic anhydrases contribute to shape $\mathrm{pH}$ changes, which can be elicited by neuronal activity, neurotransmitters and neuromodulators, metabolic processes, active cellular $\mathrm{pH}$ regulation, and secondary transporters carrying acidbase equivalents, and in turn these $\mathrm{pH}$ changes can affect neuronal functions (Deitmer and Rose, 1996; Chesler, 2003). The free $\mathrm{H}^{+}$concentration in cells is in the nanomolar range, and the high buffer capacity of cells provides a reservoir of acid equivalents in the millimolar range. In other words, there is a pool of protons in rapid exchange between buffer sites and free solution, with $10^{5}$ or more protons being buffered for each proton in solution. At a blood $\mathrm{pH}$ of 7.4, and 7.2-7.3 in the extracellular spaces of brain tissue (Cragg et al., 1977; Ruusuvuori and Kaila, 2014), and with a negative membrane potential of between -50 and $-90 \mathrm{mV}$ in mammalian brain cells, $\mathrm{H}^{+}$has to be continuously extruded to maintain a physiological cytosolic $\mathrm{pH}$ of 7.0-7.3. Nevertheless, $\mathrm{pH}$ changes may peak well outside this range, at least for short time periods, and may be considered as $\mathrm{H}^{+}$signals, sometimes even with neurotransmitter function (Deitmer and Rose, 1996; Du et al., 2014). The net extrusion of acid from neurons and glial cells is accomplished by secondary active transport, wherein the efflux of $\mathrm{H}^{+}$or the influx of $\mathrm{HCO}_{3}^{-}$is coupled to $\mathrm{Na}^{+}$ influx, utilizing energy stored in the transmembrane $\mathrm{Na}^{+}$gradient. $\mathrm{pH}$ regulation in these cells involves a variety of membrane acid-base carriers, including sodiumhydrogen exchange, sodium-bicarbonate cotransport, and sodium-dependent and sodium-independent chloridebicarbonate exchange. In addition, there are a number of acid/base-coupled carriers, which are linked to the transport of metabolites, such as lactate and amino acids. The lactate transport via monocarboxylate transporters (MCTs) has been suggested to play a major role for the supply of energy to neurons, and led to the "Astrocyte-to-Neuron Lactate Shuttle Hypothesis" (ANLSH; Pellerin and Magistretti, 1994).

\section{LACTATE SHUTTLE AND ACID/BASE TRANSPORT METABOLON}

Lactate, pyruvate, and ketone bodies are transported into and out of cells via MCTs (SLC16), of which 14 isoforms have been described. The first four of these 14 isoforms (MCT1-4) have been shown to transport monocarboxylates together with $\mathrm{H}^{+}$in a $1: 1$ stoichiometry. MCT1 is the ubiquitous isoform that is found in nearly all tissues, where it could either operate as a lactate importer or exporter, and has an intermediate $K_{m}$ value of $3-5 \mathrm{mM}$ for L-lactate (Bröer et al., 1998). MCT2, the high-affinity carrier, is mainly found in neurons, and MCT4, the low-affinity, high-capacity carrier, has been reported for glial cells in the brain.

The lactate shuttle hypothesis suggests that lactate is produced and exported by glial cells, in particular astrocytes, under normoxic conditions, and taken up by neurons for further metabolization (Pellerin and Magistretti, 1994). The ANLSH infers that astrocytes help to supply energetic substrates for neurons to meet their energy requirements, especially during enhanced neuronal activity. There is substantial evidence, both in vitro and in vivo, that lactate indeed can substitute for glucose to maintain neuronal functions, such as e.g., synaptic transmission and memory formation (Schurr et al., 1988; Suzuki et al., 2011). During energy deprivation, the addition of monocarboxylates has been shown to restore synaptic function and to be neuroprotective in vivo, in acute rodent brain slices, isolated optic nerve and neuronal cultures (Izumi et al., 1997; Schurr et al., 1997; Cater et al., 2001; Wyss et al., 2011). The finding that glucose is preferentially taken up by astrocytes and at higher rates than by neighboring neurons (Barros et al., 2009; Jakoby et al., 2014), implying that some energetic substrate has to be passed on to neurons, as they are the main energy consumers, also supports the ANLSH. More recently, lactate production and supply to neuronal axons have been suggested also for oligodendrocytes in the mammalian central nervous system 
(Fünfschilling et al., 2012; Lee et al., 2012), indicating that astrocytes and oligodendrocytes form a metabolic network with neurons to maintain neuronal function.

A transport metabolon has been defined as a supramolecular complex of sequential metabolic enzymes and cellular structural elements in which metabolites are passed from one active site to another without complete equilibration with the bulk cellular fluids (Srere, 1985). First evidence for a transport metabolon, formed between carbonic anhydrase (CA) and an acid/base transporter was found for CAII and the $\mathrm{Cl}^{-} / \mathrm{HCO}_{3}^{-}$exchanger AE1 (Kifor et al., 1993; Vince and Reithmeier, 1998). Since then, various acid/base transporters have been reported to interact with different isoforms of carbonic anhydrase: For the electrogenic $\mathrm{Na}^{+} / \mathrm{HCO}_{3}^{-}$cotransporter, NBCel, both functional (Becker and Deitmer, 2007; Schüler et al., 2011) and physical (Gross et al., 2002; Alvarez et al., 2003; Pushkin et al., 2004) interaction with different CA isoforms has been suggested. All of these interactions have in common that CA-mediated augmentation of transport activity requires the catalytic activity of the different CA isoforms.

An entirely different form of transport metabolon has first been detected, when expressing MCT1 and CAII in Xenopus oocytes (Becker et al., 2005). The presence of CAII indeed more than doubled the rate of lactate transport, and the CAII-induced augmentation of MCT activity persisted in the absence of $\mathrm{CO}_{2} / \mathrm{HCO}_{3}^{-}$, and was insensitive to inhibition of CAII catalytic activity with EZA, and was still present with the catalytically inactive mutant CAIIV143Y (Becker et al., 2005, 2011; Becker and Deitmer, 2008), suggesting that the augmentation of MCT activity does not depend on the reversible conversion of $\mathrm{CO}_{2}$ and $\mathrm{HCO}_{3}^{-} / \mathrm{H}^{+}$by CAII. No interaction between CAII and rat MCT2 could be detected, when the enzyme was injected into oocytes co-expressing MCT2 together with its trafficking protein embigin (Klier et al., 2011). Cytosolic CAII was shown to bind to the C-terminal tail of MCT1, which presumably positions the enzyme close enough to the pore of the transporter for efficient $\mathrm{H}^{+}$shuttling (Stridh et al., 2012). The binding of CAII to a glutamic acid cluster within the MCT C-terminal may also explain the isoform specificity of the interaction between MCTs and CAII, since rat MCT4, but not MCT2, possesses a similar cluster of three glutamate residues.

Augmentation of MCT activity by extracellular CAs has also been found in the brain: By inhibition of extracellular CA activity with benzolamide and an antiserum against CAIV, respectively, Svichar and Chesler (2003) could show a significant reduction in lactate-induced intracellular acidification in rat hippocampal pyramidal neurons and in cultured astrocytes.

\section{CA ACTIVITY MEDIATES BETWEEN DIFFERENT FORMS OF METABOLIC ACIDOSIS}

Carbonic anhydrases play a vital role in acid/base kinetics and mediate between acid production by oxidative phosphorylation in form of $\mathrm{CO}_{2}$ and acid production by anaerobic glycolysis. When $\mathrm{CO}_{2}$ increases in the cell, e.g., due to oxidative phosphorylation in mitochondria, it can leave the cell by freely diffusing through the cell membrane, or it can be converted to $\mathrm{H}^{+}$and $\mathrm{HCO}_{3}^{-}$, with the rate of conversion depending on catalytic activity of cytosolic CA. Most cells express CAII, which is the fastest isoform, and either CAIV and/or CAXIV, which are fast extracellular isoforms in the brain. CAIV has recently been shown to display intracellular activity in addition, which would further contribute to high intracellular CA activity (Schneider et al., 2013). With this enzymatic equipment, neurons and glial cells can produce considerable amounts of $\mathrm{H}^{+}$, which can be extruded by either NHE or MCT. Extracellular CA activity can convert part of extracellular $\mathrm{CO}_{2}$ to $\mathrm{H}^{+}$and $\mathrm{HCO}_{3}^{-}$, the latter being substrate for NBC to be transported into and out of the cell. Thus, additional $\mathrm{HCO}_{3}^{-}$can be delivered to, or removed from, the cytosol, in particular in astrocytes, which can have a robust expression of NBC, which mediates a high bicarbonate sensitivity of the cells, to further compensate metabolically produced $\mathrm{H}^{+}$(Theparambil et al., 2014).

Furthermore, both extra- and intracellular CA isoforms, as e.g., CAIV, can form transport metabolons with the bicarbonate- and proton-coupled carriers (see above). In mouse retina, CAXIV co-localized with anion exchanger isoform
3 (AE3) in Müller and horizontal cells, and physical and functional interaction between the CAXIV and AE3 was shown (Casey et al., 2009). Disruption of transport metabolon function, as suggested to occur after CAIV mutation, can interfere with photoreceptor maintenance and $\mathrm{pH}$ regulation in the retina (Yang et al., 2005; Alvarez et al., 2007). Whether other extracellular CA isoforms, which have been detected in brain tissue, also form functional metabolons with MCT and/or NBC, is still unknown. Interestingly, cytosolic CAI and CAIII, which are expressed by some cells, can enhance NBC activity in Xenopus oocytes (Schüler et al., 2011), but not MCT transport activity (Becker and Deitmer, 2008). In addition, by stabilizing the $\mathrm{H}^{+}$gradient, NBC can support lactate transport via MCT, when expressed together in oocytes (Becker et al., 2004).

From these and other results, it can be concluded that brain cells, and quite possibly other cell types in other tissues, use a whole network of acid/basecoupled membrane carriers and different CA isoforms to regulate intracellular $\mathrm{pH}$, which links acid/base status, $\mathrm{H}^{+}$buffering, energy metabolism, and $\mathrm{H}^{+} / \mathrm{HCO}_{3}^{-}$-coupled membrane transport. Thus, acid/base-coupled metabolite transport is coupled to $\mathrm{pH}$ regulation, and both are linked to CA activity and to noncatalytic functions of CA.

\section{CONCLUSIONS AND PERSPECTIVES}

Regulation of metabolism in organisms is not only complex, but also involves a large number of enzymes and membrane transporters, which may form networks to enhance their efficacy. Lactate, as a metabolic intermediate from glucose or glycogen breakdown, appears to play a major role as energetic substrate shuttled between cells and tissues, both under hypoxic and normoxic conditions. The membrane transport of lactate via monocarboxylate transporter occurs in cotransport with $\mathrm{H}^{+}$, which is a substrate, a signal and a modulator of other metabolic processes. Lactate transporter form a "transport metabolon" with carbonic anhydrases, which not only provide a rapid equilibrium between $\mathrm{CO}_{2}, \mathrm{HCO}_{3}^{-}$, and $\mathrm{H}^{+}$, but in addition enhance lactate transport by a non-enzymatic interaction, which requires physical binding as found 
in frog oocytes as expression system for the proteins involved. Carbonic anhydrases mediate between different states of metabolic acidosis, induced by glycolysis and oxidative phosphorylation, and play a relay function in coupling $\mathrm{pH}$ regulation and metabolism.

\section{ACKNOWLEDGMENT}

The work this article is base on has been supported by grants from the Deutsche Forschungsgemeinschaft.

\section{REFERENCES}

Alvarez, B. V., Loiselle, F. B., Supuran, C. T., Schwartz, G. J., and Casey, J. R. (2003). Direct extracellular interaction between carbonic anhydrase IV and the human NBC1 sodium/bicarbonate cotransporter. Biochemistry 42, 12321-12329. doi: 10.1021/bi0353124

Alvarez, B. V., Vithana, E. N., Yang, Z., Koh, A. H., Yeung, K., Yong, V., et al. (2007). Identification and characterization of a novel mutation in the carbonic anhydrase IV gene that causes retinitis. Invest. Ophthalmol. Vis. Sci. 48, 3459-3468. doi: 10.1167/iovs.06-1515

Barros, L. F., Courjaret, R., Jakoby, P., Loaiza, A., Lohr, C., and Deitmer, J. W. (2009). Preferential transport and metabolism of glucose in Bergmann glia over Purkinje cells: a multiphoton study of cerebellar slices. Glia 57, 962-970. doi: 10.1002/glia. 20820

Becker, H., Bröer, S., and Deitmer, J. W. (2004). Facilitated lactate transport by MCT1 when coexpressed with the sodium bicarbonate cotransporter (NBC) in Xenopus oocytes. Biophys. J. 86, 235-247. doi: 10.1016/S0006-3495(04) 74099-0

Becker, H. M., and Deitmer, J. W. (2007). Carbonic anhydrase II increases the activity of the human electrogenic $\mathrm{Na}^{+} / \mathrm{HCO}_{3}^{-}$cotransporter. J. Biol. Chem. 282, 13508-13521. doi: 10.1074/jbc.M700066200

Becker, H. M., and Deitmer, J. W. (2008). Nonenzymatic proton handling by carbonic anhydrase II during $\mathrm{H}^{+}$-lactate cotransport via monocarboxylate transporter 1. J. Biol. Chem. 283, 21655-21667. doi: 10.1074/jbc.M802134200

Becker, H. M., Hirnet, D., Fecher-Trost, C., Sültemeyer, D., and Deitmer, J. W. (2005). Transport activity of MCT1 expressed in Xenopus oocytes is increased by interaction with carbonic anhydrase. J. Biol. Chem. 280, 39882-39889. doi: 10.1074/jbc.M503081200

Becker, H. M., Klier, M., Schüler, C., McKenna, R., and Deitmer, J. W. (2011). Intramolecular proton shuttle supports not only catalytic but also noncatalytic function of carbonic anhydrase II. Proc. Natl. Acad. Sci. U.S.A. 108, 3071-3076. doi: 10.1073/pnas.1014293108

Bröer, S., Schneider, H., Bröer, A., and Deitmer, J. W. (1998). Characterization of the monocarboxylate transporter 1 expressed in Xenopus laevis oocytes by changes in cytosolic pH. Biochem. J. $333,167-174$.

Casey, J. R., Sly, W. S., Shah, G. N., and Alvarez, B. V. (2009). Bicarbonate homeostasis in excitable tissues: role of $\mathrm{AE} 3 \mathrm{Cl}^{-} / \mathrm{HCO}_{3}^{-}$exchanger and carbonic anhydrase XIV interaction. Am. J. Physiol. Cell Physiol. 297, 1091-1102. doi: 10.1152/ajpcell.00177.2009

Cater, H. L., Benham, C. D., and Sundstrom, L. E. (2001). Neuroprotective role of monocarboxylate transport during glucose deprivation in slice cultures of rat hippocampus. J. Physiol. 531, 459-466. doi: 10.1111/j.1469-7793.2001. 0459i.x

Chesler, M. (2003). Regulation and modulation of $\mathrm{pH}$ in the brain. Physiol. Rev. 83, 1183-1221. doi: 10.1152/physrev.00010.2003

Cragg, P., Patterson, L., and Purves, M. J. (1977). The $\mathrm{pH}$ of brain extracellular fluid in the cat. J. Physiol. 272, 137-166.

Deitmer, J. W., and Rose, C. R. (1996). pH regulation and proton signalling by glial cells. Prog. Neurobiol. 48, 73-103. doi: 10.1016/0301-0082(95) 00039-9

Du, J., Reznikov, L. R., Price, M. P., Zha, X. M., Lu, Y., Moninger, T. O., et al. (2014). Protons are a neurotransmitter that regulates synaptic plasticity in the lateral amygdala. Proc. Natl. Acad. Sci. U.S.A. 111, 8961-8966. doi: 10.1073/pnas.1407018111

Fünfschilling, U., Supplie, L. M., Mahad, D., Boretius, S., Saab, A. S., Edgar, J., et al. (2012). Glycolytic oligodendrocytes maintain myelin and longterm axonal integrity. Nature 485, 517-521. doi: 10.1038/nature11007

Gross, E., Pushkin, A., Abuladze, N., Fedotoff, O. and Kurtz, I. (2002). Regulation of the sodium bicarbonate cotransporter $\mathrm{kNBCl}$ function: role of Asp986, Asp988 and kNBC1-carbonic anhydrase II binding. J. Physiol. 544, 679-685. doi: 10.1113/jphysiol.2002.029777

Izumi, Y., Benz, A. M., Katsuki, H., and Zorumski, C. F. (1997). Endogenous monocarboxylates sustain hippocampal synaptic function and morphological integrity during energy deprivation. J. Neurosci. 17, 9448-9457.

Jakoby, P., Schmidt, E., Ruminot, I., Gutiérrez, R., Barros, L. F., and Deitmer, J. W. (2014). Higher transport and metabolism of glucose in astrocytes compared with neurons: a multiphoton study of hippocampal and cerebellar tissue slices. Cereb. Cortex 24, 222-31. doi: 10.1093/cercor/bhs309

Kifor, G., Toon, M. R., Janoshazi, A., and Solomon, A. K. (1993). Interaction between red cell membrane band 3 and cytosolic carbonic anhydrase. J. Membr. Biol. 134, 169-79. doi: 10.1093/cercor/bhs309

Klier, M., Schüler, C., Halestrap, A. P., Sly, W. S., Deitmer, J. W., and Becker, H. M. (2011). Transport activity of the high-affinity monocarboxylate transporter MCT2 is enhanced by extracellular carbonic anhydrase IV but not by intracellular carbonic anhydrase II. J. Biol. Chem. 286, 27781-27791. doi: 10.1074/jbc.M111. 255331

Lee, Y., Morrison, B. M., Li, Y., Lengacher, S., Farah, M. H., Hoffman, P. N., et al. (2012). Oligodendroglia metabolically support axons and contribute to neurodegeneration. Nature 487, 443-448. doi: 10.1038/nature11314

Pellerin, L., and Magistretti, P. J. (1994). Glutamate uptake into astrocytes stimulates aerobic glycolysis: a mechanism coupling neuronal activity to glucose utilization. Proc. Natl. Acad. Sci.
U.S.A. 91, 10625-10629. doi: 10.1073/pnas.91.22. 10625

Pushkin, A., Abuladze, N., Gross, E., Newman, D., Tatishchev, S., Lee, I., et al. (2004). Molecular mechanism of kNBC1-carbonic anhydrase II interaction in proximal tubule cells. J. Physiol. 559, 55-65. doi: 10.1113/jphysiol.2004.065110

Ruusuvuori, E., and Kaila, K. (2014). Carbonic anhydrases and brain $\mathrm{pH}$ in the control of neuronal excitability. Subcell. Biochem. 75, 271-290. doi: 10.1007/978-94-007-7359-2_14

Schneider, H.-P., Alt, M. D., Klier, M., Spiess, A., Andes, F. T., Waheed, A., et al. (2013). GPIanchored carbonic anhydrase IV displays both intra- and extracellular activity in cRNA-injected oocytes and in mouse neurons. Proc. Natl. Acad. Sci. U.S.A. 110, 1494-1499. doi: 10.1073/pnas.1221 213110

Schüler, C., Becker, H. M., McKenna, R., and Deitmer, J. W. (2011). Transport activity of the sodium bicarbonate cotransporter NBCel is enhanced by different isoforms of carbonic anhydrase. PLoS ONE 6:e27167. doi: 10.1371/journal.pone. 0027167

Schurr, A., Payne, R. S., Miller, J. J., and Rigor, B. M. (1997). Brain lactate is an obligatory aerobic energy substrate for functional recovery after hypoxia: further in vitro validation. J. Neurochem. 69, 423-426. doi: 10.1046/j.14714159.1997.69010423.x

Schurr, A., West, C. A., and Rigor, B. M. (1988). Lactate-supported synaptic function in the rat hippocampal slice preparation. Science 240, 1326-1328. doi: 10.1126/science.3375817

Srere, P. (1985). The metabolon. Trends Biochem. Sci. 13, 313-314.

Stridh, M. H., Alt, M. D., Wittmann, S., Heidtmann, H., Aggarwal, M., Riederer, B., et al. (2012). Lactate flux in astrocytes is enhanced by a non-catalytic action of carbonic anhydrase II. J. Physiol. 590, 2333-2351. doi: 10.1113/jphysiol.2011.220152

Suzuki, A., Stern, S. A., Bozdagi, O., Huntley, G. W., Walker, R. H., Magistretti, P. J., et al. (2011). Astrocyte-neuron lactate transport is required for long-term memory formation. Cell 144, 810-823. doi: 10.1016/j.cell.2011.02.018

Svichar, N., and Chesler, M. (2003). Surface carbonic anhydrase activity on astrocytes and neurons facilitates lactate transport. Glia 41, 415-419. doi: 10.1002/glia.10187

Theparambil, S. M., Ruminot, I., Schneider, H.-P., Shull, G. E., and Deitmer, J. W. (2014). The electrogenic sodium bicarbonate cotransporter NBCel is a high-affinity bicarbonate carrier in cortical astrocytes. J. Neurosci. 34, 1148-1157. doi: 10.1523/JNEUROSCI.237713.2014

Vince, J. W., and Reithmeier, R. A. F. (1998). Carbonic anhydrase II binds to the carboxyl terminus of human band 3 , the erythrocyte $\mathrm{Cl}^{-} / \mathrm{HCO}_{3}^{-}$ exchanger. J. Biol. Chem. 273, 28430-28437. doi: 10.1074/jbc.273.43.28430

Wyss, M. T., Jolivet, R., Buck, A., Magistretti, P. J., and Weber, B. (2011). In vivo evidence for lactate as a neuronal energy source. J. Neurosci. 31, 7477-7485. doi: 10.1523/JNEUROSCI.041511.2011

Yang, Z., Alvarez, B. V., Chakarova, C., Jiang, L., Karan, G., Frederick, J. M., et al. (2005). Mutant 
carbonic anhydrase 4 impairs $\mathrm{pH}$ regulation and causes retinal photoreceptor degeneration. Hum. Mol. Genet. 14, 255-265. doi: 10.1093/hmg/ ddi023

Conflict of Interest Statement: The authors declare that the research was conducted in the absence of any commercial or financial relationships that could be construed as a potential conflict of interest.
Received: 28 October 2014; accepted: 09 December 2014; published online: 05 January 2015.

Citation: Deitmer JW, Theparambil SM, Ruminot I and Becker HM (2015) The role of membrane acid/base transporters and carbonic anhydrases for cellular $\mathrm{pH}$ and metabolic processes. Front. Neurosci. 8:430. doi: 10.3389/fnins.2014.00430

This article was submitted to Neuroenergetics, Nutrition and Brain Health, a section of the journal Frontiers in Neuroscience.
Copyright (C) 2015 Deitmer, Theparambil, Ruminot and Becker. This is an open-access article distributed under the terms of the Creative Commons Attribution License (CC BY). The use, distribution or reproduction in other forums is permitted, provided the original author(s) or licensor are credited and that the original publication in this journal is cited, in accordance with accepted academic practice. No use, distribution or reproduction is permitted which does not comply with these terms. 